\title{
INGLÊS PARA TRANSGREDIR: REFLEXÕES SOBRE PRÁTICAS DE ENSINO DO PIBID PARA A PROMOÇÃO DA FORMAÇÃO INICIAL E CONTINUADA DE PROFESSORES DE LI
}

\author{
ENGLISH FOR TRANSGRESSING: REFLECTIONS ON PIBID \\ TEACHING PRACTICES IN ORDER TO PROMOTE THE INITIAL \\ AND CONTINUE TRAINING OF TEACHERS OF LI
}

Erika Vieira*

\begin{abstract}
Resumo: Considerando o subprojeto PIBID - Inglês como um locus de formação inicial e continuada de professores de língua estrangeira, objetiva-se proporcionar algumas reflexões a respeito das práticas pedagógicas produzidas pelos bolsistas e supervisores. Essas práticas coadunam-se com a perspectiva do ensino crítico da língua inglesa, tal como preconizam as OCEM (2006) e Mattos (2015), além do conceito de educação transgressora como prática da liberdade de hooks (2013). Os resultados alcançados se materializaram por meio dos relatos de algumas práticas pedagógicas que vão além do ensino de estruturas gramaticais e de práticas descontextualizadas. Tais práticas procuraram renovar os olhares para o cotidiano escolar em seu contexto social e, assim, estreitar os laços entre as escolas públicas e a formação pedagógica universitária.
\end{abstract}

Palavras-chave: Ensino de Língua Inglesa. Escola Pública. Ensino Crítico de Língua Inglesa.

Abstract: Considering the subproject PIBID - English as a locus of initial and continuing training of foreign language teachers, it is intended to provide with some reflections on the pedagogical practices produced by interns and supervisors. These practices are consistent with the perspective of critical teaching of the English language, as advocated by OCEM (2006) and Mattos (2015), as well as hooks' (2013) concept of transgressive education as a practice of freedom. The results achieved were materialized in the reports of some pedagogical practices that go beyond the teaching of grammatical structures and decontextualized practices. These practices sought to renew the eyes of ordinary school practices in its social context and, thus, to strengthen the ties between public schools and university pedagogical training.

Keywords: English Language Teaching. Public school. Critical Teaching of the English Language.

\section{Introdução}

O subprojeto PIBID - Inglês da UFVJM tem proporcionado vivências conjuntas e colaborativas, integrando a universidade, escolas de educação básica da região de Diamantina e discentes, nas figuras do coordenador de área, supervisores e bolsistas, respectivamente. Em conjunto, os envolvidos buscam desenvolver intervenções pedagógicas que possam proporcionar experiências significativas de ensino-aprendizagem de língua inglesa. Com isso, as ações do projeto envolvem o estudo e execução de práticas envolvendo o ensino crítico de língua estrangeira, as quais envolvem planejamento, execução e reflexão, de maneira que essas ações possam envolver a formação inicial e continuada dos envolvidos e contribuir para a

\footnotetext{
* Possui graduação em Letras - Licenciatura em Inglês pela Universidade Federal de Minas Gerais (2001), mestrado em Literaturas de Expressão Inglesa (2004) e doutorado em Literatura Comparada pela Universidade Federal de Minas Gerais (2012). Atualmente é professora Adjunta C da UFVJM Universidade Federal dos Vales do Jequitinhonha e Mucuri - Campus JK e membro do Centro de Estudos Shakespearianos.erikavcv@gmail.com
} 
fortalecimento do processo de ensino-aprendizagem da língua inglesa em escolas públicas da região.

Objetiva-se aqui relatar e refletir sobre algumas experiências colaborativas vivenciadas em 2017 com os participantes do projeto, sendo eles: os bolsistas representando a formação inicial - e os supervisores - representando a formação continuada -, que são os professores pertencentes à rede pública estadual de Minas Gerais. As práticas foram embasadas na perspectiva do ensino crítico da língua inglesa, tal como preconizam as OCEM (2006), os PCN (1998) e Mattos (2015), além do conceito de educação transgressora como prática da liberdade de hooks (2013). Abordase neste trabalho o ensino de língua estrangeira em escolas regulares em uma perspectiva qualitativa e etnográfica, buscando equilibrar as relações entre o local e o global, as ambivalências das mudanças da sociedade atual, a multimodalidade e os multiletramentos com vistas à promoção de mudanças das práticas pedagógicas e sociais dos licenciandos. As práticas pedagógicas implementadas refletem um desejo de ir além do ensino de estruturas gramaticais e das práticas descontextualizadas, baseadas em memorização e mera repetição de conhecimento. Por outro lado, essas propostas procuraram renovar os olhares para o cotidiano escolar em seu contexto social e, assim, estreitar os laços entre as escolas públicas e a pesquisa durante a formação pedagógica universitária.

São evidentes os desafios a serem enfrentados por participantes de processos de formação inicial e continuada de docência em língua inglesa. Dentre eles, podemos citar a carga horária reduzida destinada ao idioma de língua estrangeira, a falta de oportunidade de interação em língua estrangeira fora da sala de aula, a indisciplina e o desinteresse dos alunos, o elevado número de alunos por turma, e até mesmo o insuficiente conhecimento linguístico e cultural da língua inglesa por parte de alguns professores. Para superar esses entraves, buscou-se desenvolver intervenções interdisciplinares que promovessem a cidadania e o desenvolvimento integral do indivíduo, de maneira que ele pudesse se situar local e globalmente, aprimorando sua visão de sua própria cultura em relação a outras, de origem anglófona. A escrita dos diários reflexivos das práticas promoveu o acesso às opiniões e crenças sobre as experiências dos bolsistas que puderam identificar os conhecimentos praticados localmente sobre o processo de ensino-aprendizagem de língua inglesa e como o conhecimento didático-pedagógico se constrói a partir das perspectivas dos participantes.

\section{O ensino crítico de LI e a educação transgressora de bell hooks}

O trabalho de Mattos (2015, p. 34) chama a atenção para a desigualdade derivada do ensino deficiente de língua estrangeira no mundo globalizado. Ao nos confrontar com o questionamento sobre o significado de cidadania no mundo de hoje e o papel da escola pública e das linguagens frente às novas tecnologias, percebemos o quanto o aluno da escola pública pode ser excluído dos debates político-culturais se não tiver acesso a uma educação crítica e cidadã. Segundo a autora, a tecnologia tornou-se onipresente em nossas vidas e, por meio dela, os cidadãos globalizados fazem uso constante de práticas de leitura e escrita. Assim, saem na frente aqueles que conseguem interagir por meio da leitura e escrita em um mundo "tecnologizado" (MATTOS, 2015). Consequentemente, como bem aponta Mattos (2015, p. 35-36), as mudanças físicas e culturais promovidas pela tecnologia levam a transformações conceituais que, por sua vez, interferem na construção e desconstrução de paradigmas educacionais. 
Um dos pilares dessa mudança de paradigma que implicou em mudanças significativas no ensino de língua estrangeira é o conceito de letramento e letramento crítico. O letramento crítico pode ser associado ao desenvolvimento de consciência crítica de um texto e também ao entendimento de conceitos socialmente construídos (cf. PAPADOPOULOS \& GRIVA, 2017, p. 107). Mattos (2015, p. 89-90), corroborando as ideias de Barton (1994), observa que a ideia de letramento esteja mais associada com as atividades sociais e com uma prática associada à palavra escrita que constitui os vários eventos de letramento que ocorrem no nosso dia a dia.

Dentro dessa perspectiva, os documentos oficiais, tais como os PCN e as Orientações Curriculares Nacionais (doravante OCEM), preconizam que o ensino de língua estrangeira deve contribuir para o desenvolvimento integral do cidadão e deve pautar-se não apenas no desenvolvimento da competência linguística, mas na percepção e na prática de valores sociais (cf. BRASIL, 2006, p. 91). Ainda de acordo com esses documentos, ser cidadão implica compreender a posição que o indivíduo ocupa na sociedade e mobilizar agenciamentos em direção à inclusão social, à heterogeneidade e à diversidade cultural e linguística (cf. BRASIL, 2006, p. 95-96). Assim, os objetivos do ensino de inglês na escola pública vão muito além da memorização de palavras, da tradução de trechos descontextualizados, e do ensino de línguas por meio de estruturas gramaticais. De acordo com as OCEM, pode-se resumir que os objetivos do ensino de inglês na escola pública são:

[e]stender o horizonte de comunicação do aprendiz para além de sua comunidade linguística restrita própria (...);

fazer com que o aprendiz entenda (...) que há diversas maneiras de organizar, categorizar e expressar a experiência humana e de realizar interações sociais por meio da linguagem (...);

aguçar (...) o nível de sensibilidade linguística do aprendiz quanto às características das línguas estrangeiras em relação à língua materna $(\ldots)$

desenvolver, com isso, a confiança do aprendiz por meio de experiências bem-sucedidas no uso da língua estrangeira (...). (BRASIL, 2006, p. 92)

Tendo em vista esses objetivos, buscou-se ultrapassar os limites do conhecido ensino pautado por estruturas gramaticais e transpor as barreiras das práticas corriqueiras do aprendizado de estruturas e léxico descontextualizados. Dessa forma, propôs-se aos bolsistas de iniciação à docência a leitura e reflexão acerca da "pedagogia transgressora" de bell hooks ${ }^{1}$ (2013). Para a pensadora norte-americana, em sua obra Ensinando a transgredir (2013), a transgressão é um ato de superação e resistência às fronteiras raciais, sexuais e de classe para alcançar a liberdade. Inspirada na Pedagogia do Oprimido (1970) de Paulo Freire, hooks vê a educação como uma prática libertadora, que deve ser repensada na era do multiculturalismo.

\footnotetext{
${ }^{1}$ bell hooks é o pseudônimo da norte-americana Gloria Jean Watkins (Hopkinsville, 25 de setembro de 1952), que tomou emprestado o nome de sua bisavó maternal, como uma forma de homenageá-la. Interessante notar que as iniciais de seu nome artístico não levam letra maiúscula. Aclamada intelectual, escritora, feminista, ativista, crítica cultural e artista. Publicou vários livros de diversos gêneros diferentes. Sua escrita versa sobre temáticas de gênero, raça, classe, espiritualidade, educação, e o significado das mídias na cultura contemporânea. Entre suas obras estão: Ain't I a Woman: Black Women and Feminism, Rock My Soul: Black People and Self-Esteem, Teaching to Transgress: Education as the Practice of Freedom, Feminism Is for Everybody: Passionate Politics, Teaching Community: A Pedagogy of Hope, Where We Stand: Class Matters, and We Real Cool: Black Men and Masculinity.
} 
Assim, no capítulo intitulado "Pedagogia engajada", hooks (2013, p. 25-36) descreve como o professor participa do crescimento intelectual do aluno em uma educação que tem como princípio a prática da liberdade. Ao desafiar o sistema da educação bancária de mero acúmulo de conhecimentos, ela propõe estratégias de conscientização em sala de aula, em que ela e os alunos são participantes ativos e não canais, receptores e acumuladores de informação. Com a pedagogia engajada, propõe-se que os professores estejam ativos em um processo de auto atualização de modo que se promova o bem-estar de todos. Só assim poderão ensinar de modo a fortalecer e capacitar os alunos, relacionando o que aprendem com suas experiências de vida, o que permite que sejam responsáveis por suas escolhas. Ela enfatiza que na pedagogia engajada não só o aluno se beneficia, mas também o professor que se propõe a um eterno processo de busca pelo conhecimento.

No que se refere mais especificamente ao ensino-aprendizagem de língua estrangeira, Urzêda-Freitas (2012), leitor de hooks, aborda o educar para transgredir de maneira ampliada ao campo de conhecimento linguístico. Assim, "transgredir" é levar o aluno também para o extralinguístico, por meio da troca de conhecimentos de maneira contextualizada e politizada. Segundo o autor, "a pedagogia como transgressão se concretiza no pressuposto de que não basta ensinar uma língua para fins comunicativos: é preciso considerar os efeitos/valores que essa língua produz na sociedade" (URZÊDAFREITAS, 2012, p.79). O autor afirma que seu propósito era possibilitar o uso da língua estrangeira para refletir sobre temas de caráter político-social, tais como classe, raça, etnia, gênero, sexualidade etc. (URZÊDA-FREITAS, 2012, p.80). Assim, o professor buscou, em caráter experimental, levar seus alunos a refletirem e reconhecerem as diferentes identidades existentes na sociedade como um ato de autoconhecimento, resistência e empoderamento (p.81). O objetivo de Urzêda-Freitas (2012) era contrapor a abordagem crítica no ensino de língua estrangeira ao ensino comunicativo, cujo propósito centra-se principalmente nas competências linguísticas. Ao propor que seus alunos refletissem sobre problemas político-sociais nas aulas de língua estrangeira, aproximando os tópicos ao contexto social deles, ele integra o aprendizado de competências linguísticas ao impacto positivo dessas discussões na realidade e individualidade dos alunos. O professor afirma que "um dos principais objetivos do ensino crítico de línguas é suscitar a dúvida por meio do diálogo e da problematização das desigualdades sociais, e não exatamente converter ou convencer os alunos" (Urzêda-Freitas, 2012, p. 91, destaques do autor). O processo de trocas de ideias torna-se, assim, crucial para que se tenha um ambiente de aprendizado e formação críticos.

Enfim, o artigo de Urzêda-Freitas (2012) nos permite perceber que o ensino crítico em línguas estrangeiras é possível e traz bons resultados, porém demanda esforço por parte dos professores, visto que os temas abordados são polêmicos e podem causar estranhamento e recusa dos alunos. Portanto, os relatos descritos em seu artigo são importantes para mostrar que existe a chance de se alcançar sucesso por meio dessa forma de ensino e pode servir de incentivo a outros profissionais, como foi o caso das intervenções do nosso projeto.

\section{Intervenções}

Neste trabalho não nos filiamos a um método específico. Ao atrelar o projeto a um método ou a uma metodologia, incorre-se o risco de limitar a visão dos participantes a uma única visão do ensino de língua estrangeira, além de considerá-lo como superior e 
infalível por ter sido criado fora da escola. Assim, foi preciso lançar mão de vários métodos e abordagens, considerando sempre as especificidades de cada contexto. Contudo, as práticas tiveram como base os pressupostos apresentados nas Orientações Curriculares para o Ensino Médio (OCEM, 2006).

No que se refere ao planejamento das intervenções, as ações se basearam em um ciclo de diagnóstico, tratamento e avaliação, tal como proposto por Douglas Brown (2002). Assim, os sujeitos precisavam identificar as deficiências e problemas de ordem linguística, crítica ou comportamental (fase diagnóstica), planejar e executar ações pedagógicas voltadas para a superação dessas deficiências (tratamento), e depois refletir sobre essas ações por meio de relatórios e diários reflexivos, apontando os pontos fortes e fracos, de maneira que a prática pudesse ser aperfeiçoada.

Diante dessa moldura metodológica, segue-se adiante os relatos do desenvolvimento de quatro práticas desenvolvidas.

\subsection{Projeto: "We are Family!"}

Propôs-se o estudo do léxico sobre os membros da família em inglês por meio da produção do gênero árvore genealógica com os alunos do $6^{\circ}$ ano do ensino fundamental, de modo a tornar o aprendizado desse tópico mais personalizado e significativo para os estudantes. Objetivou-se promover uma prática de vocabulário da língua estrangeira e mostrar a importância da família no processo de desenvolvimento do aluno. Promoveu-se uma discussão sobre a importância da família para o desenvolvimento humano e salientou-se a prática de respeito às diferenças, visto que família é algo único para cada um e possui diferentes tipos de composição na sociedade. Os alunos elaboraram uma lista de palavras dos membros da família em inglês. Algumas palavras presentes na lista eram: mother, father, sister, brother, grandma, grandpa, uncle, aunt, cousin, etc. Para sedimentar um pouco mais o conhecimento do vocabulário do aluno, foi entregue um Wordsearch (Caça-palavras) com o mesmo tema. Depois de uma explicação sobre "Family Tree", cada aluno recebeu uma folha em branco para a confecção da sua própria árvore genealógica. Foi possível observar que durante a prática proposta, houve grande empenho dos alunos nas atividades, pois os estudantes se mostraram inteirados com o tema. Também se verificou que promoveu o autoconhecimento dos alunos ao poderem manusear o conhecimento lexical sobre sua própria origem. Ao fim, concluiu-se que havia diversidade de estruturas familiares, que nem sempre era compostas apenas por mother, father, brother and sister como se vê com frequência em alguns livros didáticos. As discussões em sala de aula contribuíram para a desmistificação desse estereótipo em que a mãe ou a avó eram as chefes de família. Os trabalhos realizados foram expostos na área externa da escola. 


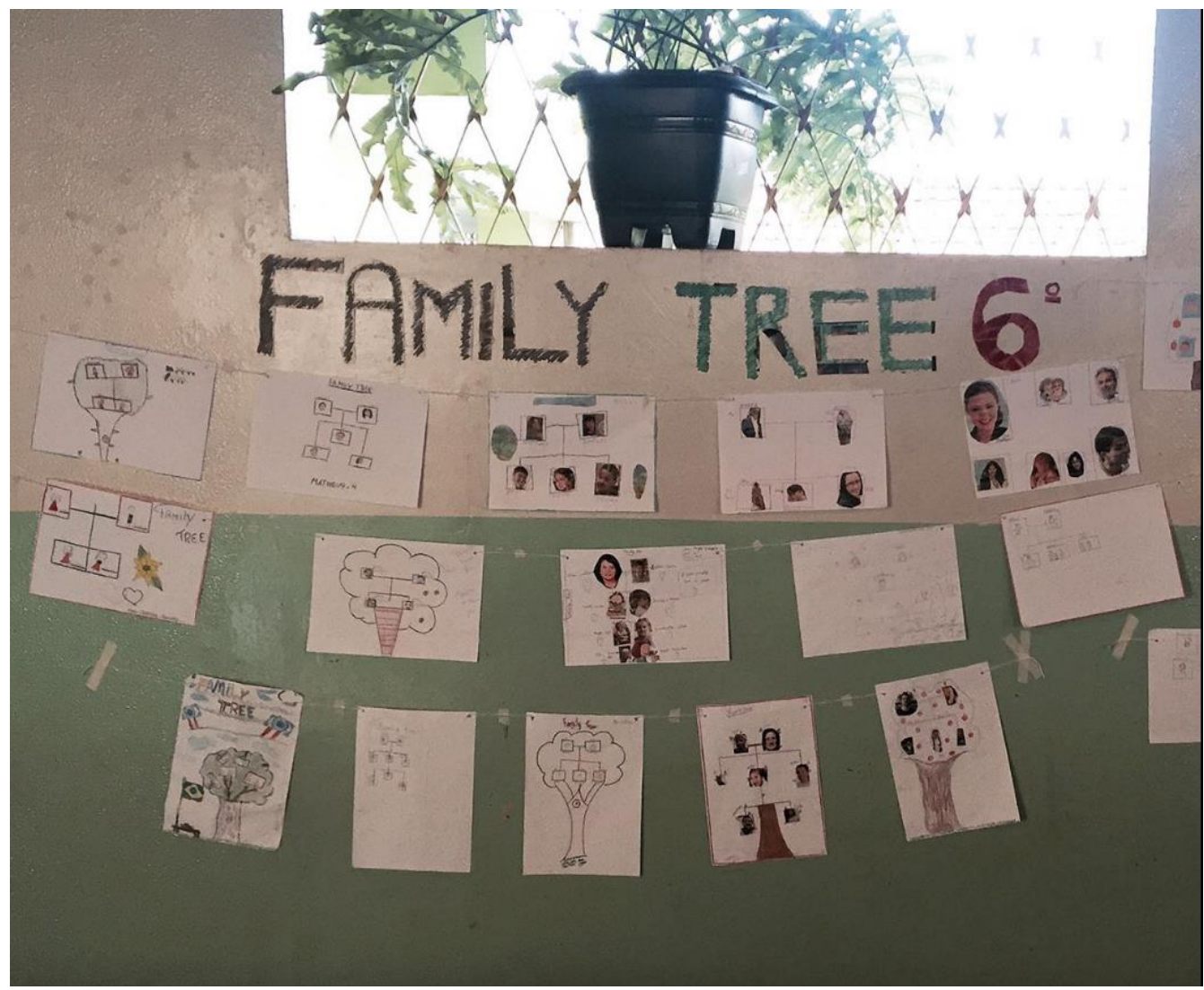

Fig. 1: Intervenção "We are Family!” . Fonte: acervo pessoal do autor.

\subsection{Projeto: "No more prejudice"}

Observou-se que o tema "preconceito" era relevante ser tratado e propôs-se apresentá-lo às turmas de $1^{\circ}$ ano do Ensino Médio, em uma intervenção de 3 aulas de 50 minutos cada. Na primeira aula, explicou-se aos alunos a temática do projeto e seus objetivos; em seguida, foi mostrado aos alunos um curta brasileiro amador, sem diálogos, chamado "O Preconceito Cega". Após assistirem ao vídeo, os alunos deram início à discussão sobre o preconceito racial, com perguntas direcionadas pelos professores.

$\mathrm{Na}$ aula seguinte, foi realizada uma atividade de caça-palavras (word search) com o propósito de trabalhar com o léxico relacionado ao vídeo. Entregamos aos estudantes uma lista com 12 palavras em português relacionadas ao tema (preconceito, etnia, rico, pobre, negro, mulher, diferente, feio, belo, injustiça, homossexual e estereótipo) e os alunos deveriam encontrar as palavras correspondentes em inglês dentro do caça-palavras.

A segunda etapa do projeto consistiu na leitura e discussão guiada do poema "I, too" de Langston Hughes, que foi contemplado no ENEM de 2012. Esse poema foi escolhido porque aborda o preconceito em uma sociedade e em uma época diferente da que vivemos. A análise do poema e da questão da prova do ENEM permitiu abordar um pouco do que foi a segregação racial nos Estados Unidos da América e fazer uma reflexão sobre o preconceito no Brasil, mais especificamente na cidade de Diamantina, Minas Gerais.

$\mathrm{Na}$ última etapa/aula do projeto propôs-se a realização de uma campanha de conscientização contra o preconceito com a confecção de cartazes contendo imagens recortadas de revistas ou ilustrações, desenhos feitos à mão e mensagens contra o 
preconceito, escritas pelos próprios alunos, em língua inglesa. Após a revisão linguística, expomos os trabalhos dos alunos em um mural da escola, em que todos os alunos, professores e funcionários pudessem ter acesso à mensagem de tolerância e diversidade.
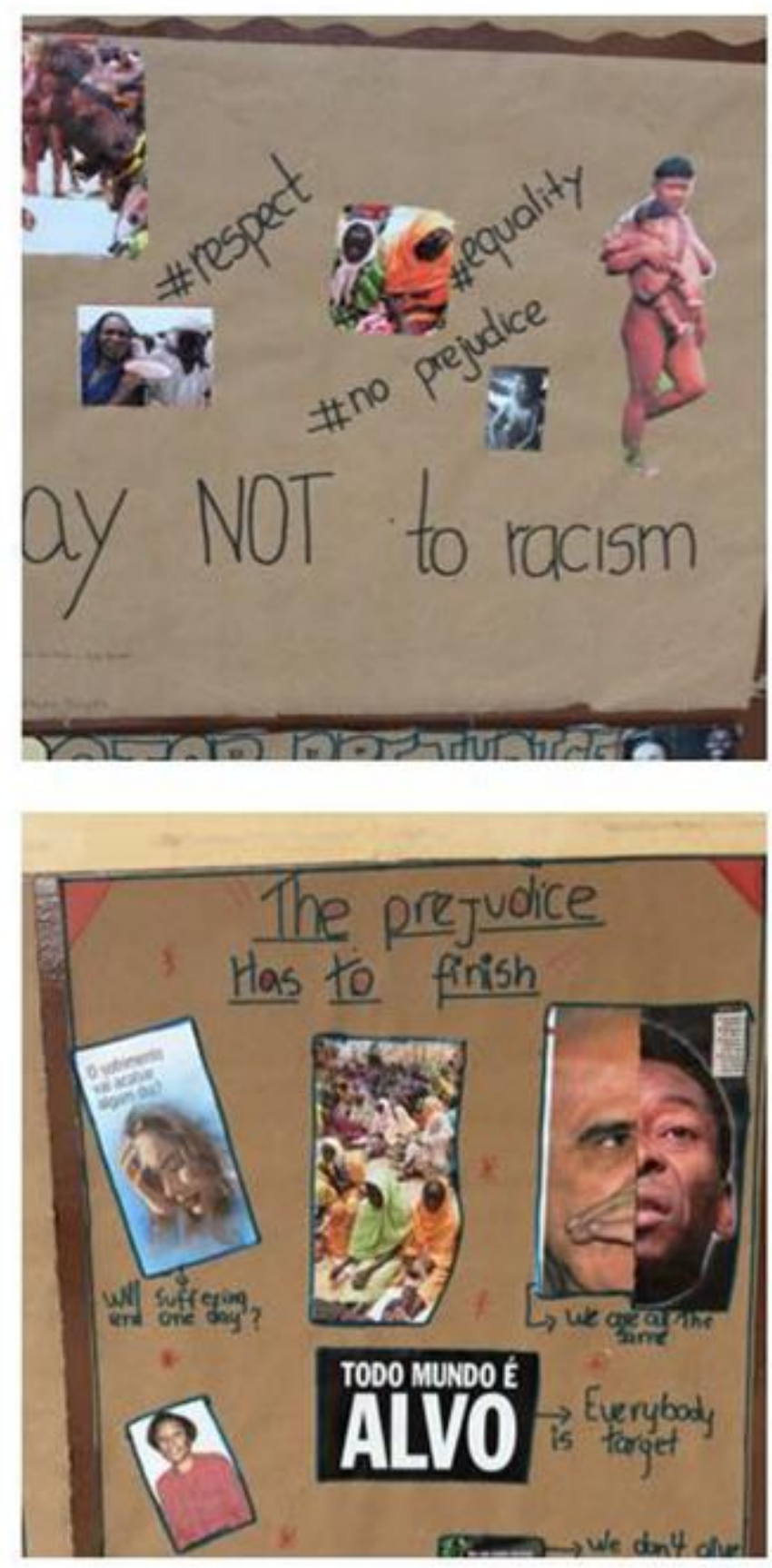

Fig. 2: Projeto "No More Prejudice!" . Fonte: acervo pessoal do autor.

\subsection{Projeto: "Stop Bullying"}

Sendo o bullying um assunto amplamente discutido na atualidade e devido às consequências negativas dessa prática na vida dos estudantes que vivenciam tal experiência, foram realizadas atividades voltadas à sua prevenção dentro e fora do meio 
escolar juntos aos alunos de uma turma de $9^{\circ}$ ano. A intervenção foi dividida em quatro aulas, nas quais foram trabalhadas as habilidades de leitura e escrita relacionadas aos textos base sobre bullying estudados na primeira etapa. Nesse intuito, o tema foi escolhido a fim de desenvolver o pensamento crítico dos estudantes sobre as responsabilidades de seus próprios atos enquanto indivíduos que têm influência na vida daqueles com quem convivem.

Na primeira parte, abriu-se um espaço para uma discussão sobre o bullying, a partir das seguintes perguntas: "O que vocês sabem sobre o bullying?" "Qual a origem dessa palavra" "Como podemos evitar essa prática?". Isso permitiu que os alunos conhecessem a origem de língua inglesa da palavra, falassem o que sabiam a respeito do tema, além de relatar suas experiências como vítimas ou praticantes de bullying. Depois disso, foram distribuídos aos alunos os textos em língua inglesa e foi sugerido que localizassem nele as palavras que conheciam ou cognatas, a fim de estimular uma estratégia de leitura que facilitasse a compreensão daquele e de futuros trabalhos escritos em línguas estrangeiras. Depois, foram trabalhadas as estratégias de leitura global e específica, além de produção de inferências. Ao fim da aula, os alunos foram orientados a guardarem consigo os textos, já que os utilizaríamos nas próximas aulas.

\title{
BULLYING
}

Bullying often starts when people pick on something about you that is different. It can be how big you are, the color of your skin, the way you act or speak, for example.

If this happens to you, tell someone you trust: a friend, a teacher and/ or your parents. During breaks and lunch time, try to stay in safe areas of the school with your friends or many other people. If someone hurts you, tell a teacher immediately and make sure you tell your parents. If you're acting like a bully, think about your acts and consider respecting people the way they are.

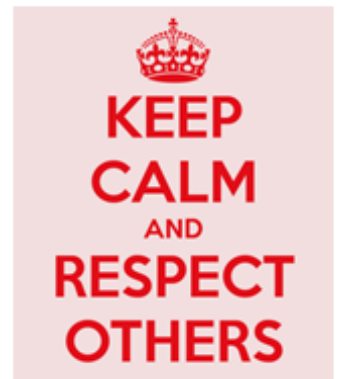

\author{
" $6+3=9$ \\ But so does $5+4$
}

The way you do things is not always the only way to do them. Respect other's people way of thinking."

Fig. 3 Texto da primeira aula. Fonte: acervo pessoal do autor.

Em um segundo momento, foram entregues aos alunos os caças-palavras com vocabulário referente ao texto trabalhado na primeira aula com o objetivo de trabalhar palavras-chave relacionadas ao tema que poderiam ser usadas em produções posteriores. Os estudantes deveriam, assim, encontrar as palavras em inglês. Ao todo, foram confeccionados 5 tipos de caça-palavras com o mesmo vocabulário, porém com diferentes combinações. Ao fim da aula, as atividades foram corrigidas coletivamente. 

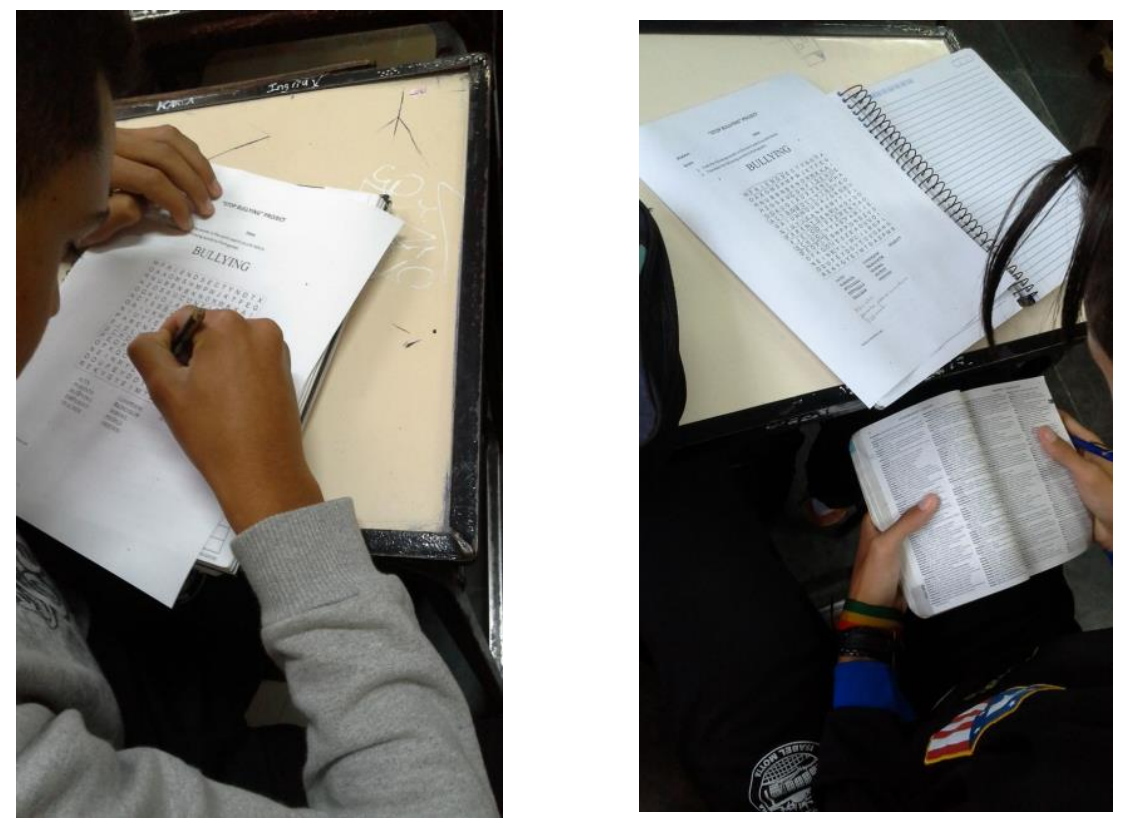

Fig. 4. Alunos do $9^{\circ}$ ano resolvendo os caça-palavras sobre bullying. Fonte: acervo pessoal do autor.

Por fim, os alunos foram separados em 5 grupos de 6 integrantes e cada equipe orientada a elaborar dois cartazes em língua inglesa: um deveria ser sobre o conceito de bullying e o outro, sobre como evitar essa prática. Durante a produção, os alunos foram monitorados e auxiliados pelos bolsistas durante a elaboração das frases em inglês para escreverem nos cartazes, além de sugerir ideias, tais como imagens e desenhos que poderiam ilustrar o cartaz. Foi sugerido também que utilizassem palavras do vocabulário trabalhado nas aulas anteriores sobre bullying. Ao final da aula, os cartazes foram expostos na parede do pátio da escola para que todos pudessem visualizá-lo.

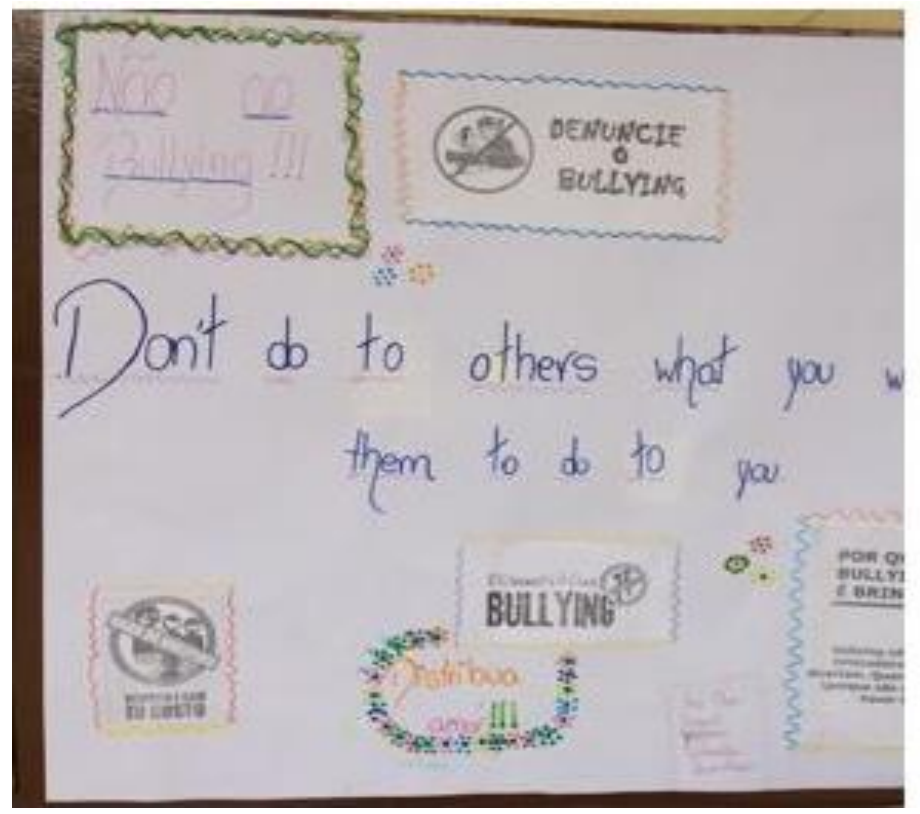

Fig. 5 Cartazes confeccionado pelos alunos. Fonte: acervo pessoal do autor.

3.4 Projeto "Modern Slavery" 
Este projeto foi baseado no conteúdo apresentado em sala pela professora supervisora sobre o Dia do Trabalhador (Labor Day). Considerando o contexto local e social dos alunos, a temática do trabalho foi considerada relevante a ser apresentada aos alunos do $8^{\circ}$ ano do ensino fundamental. Portanto, a prática foi proposta para que os alunos pudessem refletir criticamente sobre o impacto das pequenas ações usando a língua estrangeira.

No primeiro momento, foi realizada uma discussão a respeito do Labour Day: suas origens e a importância de refletir sobre a data. Em seguida, foi passado um texto introdutório sobre o tema que seria trabalhado. No texto, foram procuradas palavras cognatas e falso cognatas para que os alunos pudessem inferir sobre o tema que iria ser trabalhado. Em seguida, foi questionado o que eles sabiam sobre o tema e qual palavra mais se repetia no texto.

Em seguida, foram escritos no quadro nomes de algumas marcas famosas e foi perguntado o que eles sabiam sobre as condições de produção dos produtos dessas empresas. "O que produzem? Os alunos consomem produtos dessas empresas? O que elas têm em comum?". Foi feita uma reflexão histórica com os alunos sobre o contexto do início da escravização até a sua abolição no século XIX. Os estudantes foram questionados nessa etapa sobre o que eles sabiam sobre o trabalho forçado nos tempos atuais. Em seguida, foram explicadas as ações de grandes empresas e seus papéis na manutenção de condições precárias de produção de produtos industrializados.

$\mathrm{Na}$ etapa seguinte escreveu-se no quadro alguns tipos de Modern Slavery, como: child slavery, human trafficking, forced labor, dept bondage, forced marriage. Em seguida, foi questionado se os estudantes conseguiam identificar algum desses modos de "escravização" nos dias atuais. Após essa reflexão, cada tipo de Modern Slavery foi contextualizado à situação brasileira e onde poderiam ocorrer práticas dessa natureza. Foram relembradas aos alunos as políticas brasileiras de proteção à criança, por meio do Estatuto da Criança e do Adolescente (ECA). Ao final da aula foi pedido que os alunos formassem oito grupos com quatro componentes, e explicada a proposta de criação de uma campanha contra o Modern Slavery por meio de cartazes.

$\mathrm{Na}$ terceira aula, foi pedido que os alunos se agrupassem e procedessem ao desenvolvimento de cartazes contendo campanhas contra a escravização moderna utilizando o vocabulário novo. Durante a execução da campanha, os alunos foram auxiliados e monitorados no processo da escrita em língua inglesa. Após a finalização da campanha o mural foi colado em local de grande circulação da escola. Em seguida, foi passada atividade complementar, com foco na gramática trabalhada no decorrer da prática. Foram trabalhadas questões sobre o Simple Past, identificação de palavras cognatas e elaboração de um acróstico com o tema Freedom. Os alunos foram auxiliados na produção do acróstico. Ao final da aula, as atividades foram corrigidas e a prática finalizada.

[texto 01]

Contemporary slavery takes various forms and affects people of all ages, gender and races.

Slavery did not end with abolition in 19th century. Modern Slavery can be present in our society and harms people all over the world.

Slavery continues today in every country in the world. Women are forced into prostitution. People are forced to work in agriculture, domestic work, and factories. Children produce goods that are sold globally. Entire families are forced to work to pay off generation debts. Girls may get married to older men to pay family debts.

The International Labor Organization (ILO) estimates that around 21 million people around the world are in slavery. This includes 5,5 million children. 
Fig. 6 Texto sobre Modern Slavery. Fonte: acervo pessoal do autor.
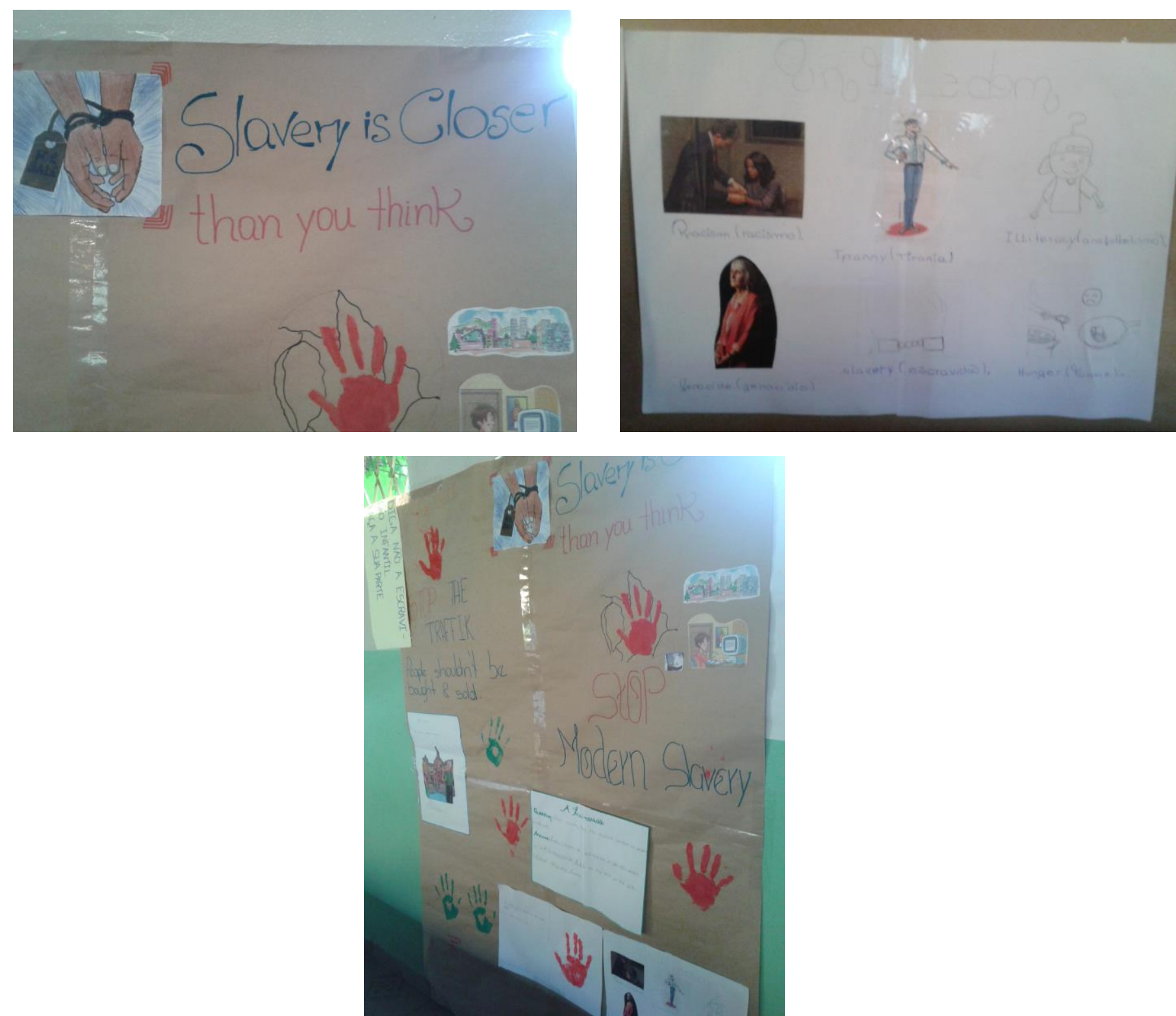

Fig. 7. Texto da primeira aula. Fonte: acervo pessoal do autor.

\section{Considerações Finais}

Nas práticas elencadas, entre várias outras que foram desenvolvidas, observa-se uma prática de desenvolvimento de temas transversais, contextualizados, que buscam "transgredir", nos termos de hooks, (2013), o ensino de línguas estrutural, descontextualizado e despersonalizado. As discussões sobre família, preconceito racial, bullying e trabalho escravo buscaram trazer esses debates para a realidade próxima dos alunos da mesma maneira que essas discussões se enriqueceram ao serem iluminadas pelas experiências prévias dos 
alunos. Entre as experiências positivas relatadas pelos bolsistas ID e pelos supervisores foram o espaço dado aos alunos para se expressarem e o aprendizado ocorrer de "maneira diferente", mais politizado.

Contudo, observa-se ainda um gap entre o que é preconizado principalmente pelas OCEM e a realidade da prática escolar. Embora as práticas intervencionistas propostas pelos sujeitos tanto em formação inicial quanto continuada expressem um desejo de implantação de práticas socioeducativas e a inclusão de temas transversais de maneira inovadora, as concepções de língua como código, a obrigatoriedade de avaliação formativa e somativa, falta de recursos tecnológicos, e pouco conhecimento de logística e gerenciamento de sala de aula ainda interferem no sucesso dessa abordagem. Assim, apesar do esforço empreendido em implementar o letramento crítico, este ainda se mostra comprometido por diversas razões relacionadas à pouca experiência dos participantes. Ao reconheceram que as práticas implementadas foram um aprendizado "diferente", os estudantes denunciaram que a maioria das aulas giravam em torno de textos ou de estruturas gramaticais.

No que se refere à concepção de língua, é visível que os sujeitos envolvidos ainda estão atrelados a uma concepção de língua como código, como estrutura, que precisa ser "decifrado" e que estão presentes apenas no texto estudado. Assim, ainda é notório o uso extensivo de textos, listas de palavras e atividades com tradução. $\mathrm{O}$ trabalho com gêneros também se mostra tímido e muito associado aos gêneros escritos, o que foi perceptível na produção de apenas um gênero: cartazes. Há ainda uma certa timidez de se trabalhar com os gêneros orais em sala de aula, tanto de produção quanto de recepção. Isso se deve ao fato de que a proficiência linguística ainda é um assunto delicado dos cursos de graduação em licenciatura em Letras, o que não permite que o licenciando a aborde com segurança nas práticas educativas. Na verdade, a formação inicial não dá conta desse quesito e o professor, depois de formado, nem sempre tem oportunidade de melhorar e se manter atualizado. Atrelado a esse fato, como consequência ou não da falta de proficiência, está o fato de as intervenções relatadas serem, em sua maioria, em língua portuguesa. Muitos dos envolvidos relataram que mesclam os termos aprendidos em língua estrangeira à discussão em língua portuguesa. Porém, conduzir a discussão dos temas apenas em língua estrangeira foi relatado como desconfortante e de grande dificuldade. A língua estrangeira como meio de comunicação e não como objeto de aprendizado descolado da realidade ainda é um desafio.

Quanto ao tipo de avaliação, observou-se que ainda há necessidade de medir o aprendizado por meio de "provas" de natureza formativa e somativa, sendo a divisão de pontos definida pelo Projeto Pedagógico da escola, segundo relatos das professoras supervisoras. Tal imposição compromete a concepção de conhecimento significativo, atrelado à realidade do aluno, contextualizado, e que possa ser avaliado de maneira processual. $\mathrm{O}$ fato de o professor ser "obrigado" a transmitir aos seus alunos uma concepção de linguagem conteudista, como "matéria de prova" que deve ser memorizada, limita o raio de ação do professor e dos iniciantes à docência, pois os temas transversais e as discussões precisam se tornar "conteúdo" avaliativo.

Chegamos a mencionar que um dos objetivos do subprojeto PIBID de Inglês era trabalhar com os "multitletramentos". Essa noção de letramentos múltiplos envolvendo não apenas a leitura e escrita, mas também as questões midiáticas, culturais e sociais, hoje, mostram-se comprometida se não inclui também as novas tecnologias. É notório que algumas escolas públicas não oferecem condições materiais para a execução de intervenções que envolvam essas novas tecnologias. Assim, nenhuma intervenção foi capaz de trazer questões relacionadas às redes sociais, interatividade virtual ou de caráter online porque as escolas conveniadas não ofereciam infraestrutura suficiente para que práticas de letramento digital pudessem ser realizadas. 
Por fim, uma outra dificuldade percebida estava relacionada à logística e ao gerenciamento da sala de aula e este tópico se sobressai entre os iniciantes. Verifica-se que a inexperiência está atrelada também à falta de conhecimento de técnicas e estratégias para lidar com situações inesperadas e de falhas de planejamento. Nos relatos reflexivos dos participantes foi quase unanimidade o fato de que o tempo estimado para as práticas não havia sido suficiente para a execução, seja pela indisciplina seja pela impossibilidade de prever a complexidade das propostas frente o nível linguístico dos estudantes. Dessa forma, foi necessário conscientizar os licenciandos da necessidade de um planejamento mais detalhado.

Contudo, as experiências relatadas nos mostram que é possível personalizar as experiências de aprendizado, de modo a trazer debates da ordem do dia em língua estrangeira para a realidade do estudante, tornando seu aprendizado mais significativo, como foi o caso da prática com as árvores genealógicas sobre a família. Nesta prática, pôde-se descobrir que cada família era única e especial, e nem sempre correspondia às configurações familiares convencionais. Ao abrir-se o espaço para a diversidade, os estudantes demonstraram maior envolvimento com o aprendizado do vocabulário relacionado à "família".

Com relação à prática relacionada ao bullying, a intervenção serviu para conscientizar os estudantes, tanto aqueles que eram vítimas quanto os praticantes, que finalmente puderam conhecer a origem do termo, identificar a prática e solicitar ajuda. Esta prática esteve relacionada a outra que promoveu a discussão sobre o preconceito racial. Ao associar a discussão do preconceito racial ao poema de Langston Hughes e à questão da prova oficial, os estudantes puderam perceber que a questão está na ordem do dia e que era necessário conhecê-la bem para construir argumentos favoráveis ou contrários à presença do preconceito na sociedade brasileira, bem como identificar situações preconceituosas. Não muito diferente está a discussão a respeito das situações degradantes de trabalho proposta pela temática da escravidão moderna, a qual promoveu uma reflexão sobre trabalho infantil, trabalho forçado e condições impróprias de trabalho a que algumas pessoas são expostas.

Com essas atividades, o PIBID - Inglês alcançou seu objetivo primordial que foi implementar novas práticas que permitissem a formação de cidadãos mais conscientes. Embora o aspecto lexical tenha sido mais enfatizado que o aprendizado de estruturas verbais, observou-se que esse fato não foi empecilho para a produção textual dos cartazes de conscientização no ambiente escolar. Ao contrário, verificou-se maior envolvimento dos estudantes e crescente desejo de se expressarem na língua estrangeira, demonstrando que a liberdade transgressora de hooks (2013) é capaz de promover o crescimento intelectual e social dos alunos, fazendo com que eles pudessem refletir a respeito de temas variados de caráter político-social.

\section{Referências}

BRASIL. Parâmetros curriculares nacionais: terceiro e quarto ciclos do ensino fundamental: língua estrangeira. Secretaria de Educação Fundamental. Brasília: MEC/SEF, 1998. p. 69 110.

BRASIL. OCEM - Orientações curriculares para o ensino médio: Linguagens Códigos e suas Tecnologias. Secretaria de Educação Básica. Brasília: Ministério da Educação, Secretaria de Educação Básica, 2006.

BROWN, H. D. English Language Teaching in the "Post-Method" Era: Toward Better Diagnosis, Treatment, And Assessment. In.: RICHARDS, J.C. \& RENANDYA, W. A. (Ed.). 
Methodology in Language Teaching: An Anthology of Current Practice. New York: Cambridge UP, 2011, p. 9-18.

HOOKS, B. Ensinando a transgredir: a educação como prática da liberdade. Trad. de Marcelo Brandão Cipolla. São Paulo: WMF Martins Fontes, 2013.

MATTOS, A. M. A. Ensino de inglês como língua estrangeira na escola pública: letramentos, globalização e cidadania. Jundiaí: Paco Editorial, 2015.

PAPADOPOULOS, I; GRIVA, E. Promoting Critical Literacy in the EFL Context: Implementing A Project to Young Learners. European Journal of Language and Literature Studies, vol 7, n. 1, p. 107-120, Jan-Apr. 2017.

URZÊDA-FREITAS, M. T. de. Educando para transgredir: reflexões sobre o ensino crítico de línguas estrangeiras/inglês. Trab. linguíst. apl., vol.51, n.1, p.77-97, 2012.

Recebido em 12 de outubro de 2018

Aceito em 17 de novembro de 2018 